\title{
UTILIZATION OF INTERNET SOCIAL MEDIA SITES: STUDENTS' PERSPECTIVE
}

\author{
Olivera Grljević $^{1}$, Zita Bošnjak ${ }^{2}$
}

\begin{abstract}
Intensive internet and social media sites usage has posed certain changes in modern business, particularly regarding relationship with customers. More successful companies have already embraced these possibilities and changes, and improved their overall business strategies. Higher Education Institutions as services providers can also benefit from internet social media sites, particularly in the field of enrollment strategy and attraction of prospective students. Analysis of user generated contents on social media sites can provide the institution with the better insights on its reputation, students' opinion, preferences, and attitudes regarding the services they provide. It could also provide better groundwork for improvement of its relationship with students. Since different user personalities engaging in social media conversations comprise variety of groups and different usage profiles, the goal of this article is to evaluate the usage of social media sites among students and to identify different user profiles among prospective students for the Faculty of Economics Subotica, Serbia.
\end{abstract}

JEL Classification Numbers: D83, D85, C38, DOI: http://dx.doi.org/10.12955/cbup.v2.484

Keywords: Social media, internet, analytics, clustering

\section{Introduction}

Extensive use of internet social media sites (blogs, forums, social networks, and other sites that allow people to connect and share content) is reflected in company businesses, as well as development and maintenance of qualitative relationships with customers. The use of social media has dramatically changed the profile of the average consumer. The internet, as well as social media sites, has made information about products and services omnipresent, and consumers are better informed. As a result, companies are faced with consumers who know exactly what they wish for, and who want to participate in the exchange of the ideas and new product design through social media sites, (Grljević \& Bošnjak, 2012). Additionally, information sharing and exchange of consumer experiences is available on the go through networking and connectivity over these sites; therefore, the good and bad reviews are spread very rapidly.

More convenient and easier problem solving and exchange of opinion about products and services with other users represent two of the most common reasons for social media use. Additionally, companies must not forget that a large percentage of online users strongly believe in recommendations and opinions of their (online) friends. According to one study by Lithium (2012), the number of such users consists of $80 \%$ consumers. So, word-of-mouth marketing in the context of social media is powerful.

One of the main problems of modern business is a different perception of the company and customers on the reasons and motives for joining companies' online community and general use of social media sites. Companies that do not observe these reasons in the right manner and do not realize that it is about loyal customers who are looking for a unique experience with the company through social media sites will not successfully meet the needs of customers in the modern business environment.

Therefore, the main objective of any company (in planning marketing strategy that will incorporate the advantages of social media sites usage) is to observe and learn about the changing profile of its customers, to understand the ways in which users connect through the internet, as well as their motives for networking, and then to conceptualize business strategies as a response to the customers' actions.

Higher Education Institutions, as service providers, should also take advantage of social media sites utilization and possibilities brought by analyses of their contents. Both former and current students exchange information about faculty on forums, Facebook pages, and other social media sites, as well

\footnotetext{
${ }^{1}$ Olivera Grljević, University of Novi Sad, Republic of Serbia, oliverag@ef.uns.ac.rs

${ }^{2}$ Zita Bošnjak, University of Novi Sad, Republic of Serbia, bzita@ef.uns.ac.rs
} 
as about courses they attended, exams taken, experiences, and general impression of the faculty. Analysis of such content can provide the institution with the better insights on its reputation, students' opinion, preferences, and attitude regarding the services the institution provides. It could provide better groundwork for improvement of its relationship with students and for tailoring the offer in accordance to students’ preferences and market needs (Grljević \& Bošnjak, 2012).

Regarding the aforementioned, surveys have been conducted among prospective students of Faculty of Economics Subotica, Serbia, with the aim to better understand online behavior of students, and obtain better insight into students' motives for networking through social media sites, as well as the intensity of use of these sites in education and training. This article illustrates the results of these investigations.

The structure of this article is as follows. The Literature Review section reviews relevant literature that motivated the research presented in this article. In the Research Fundamentals section, some fundamental criteria are set, i.e. research questions, population, research instruments, etc. The Research Results section briefly describes and summarizes some of the research results. The last section presents the conclusion and future research directions.

\section{Literature Review}

Although the use of social media sites is widespread, little is known about the analysis of user generated, the potential and the benefits their use can bring to Higher Education Institutions. These benefits are particularly present in the context of marketing, attracting new students, and learning and student engagement.

The initial steps of researches, such as Pearson Social Media Survey (2010), Junco (2011), Chuck (2012), and Ologie (2012), refer to the analysis of the current situation and different ways of internet social media websites use by students and teachers:

- Which social media sites faculty stuff use for personal communication, professional use and teaching, as well as the value which college faculty find in using these online spaces is presented in Pearson Social Media Survay (2010). As the results showed Facebook and YouTube are the most popular among faculty stuff for either use.

- The relationship between frequency of Facebook use, participation in Facebook activities, and student engagement was analyzed in Junco (2011). The results showed the Facebook use was significantly negatively predictive of engagement scale score and positively predictive of time spent in co-curricular activities.

- Research presented by Chuck (2012) examined potential correlation between heavy usage of social media and grades. The results proved that there was no correlation, grades followed similar distributions for all colleges, with majority of students having highest grades.

- Review of the way people use social media in general and at colleges and universities, Ologie (2012), showed that Americas colleges and universities, as an early adopters of social media, outblog the business world. In 2008, 13\% of fortunate 500 companies used blogs, 39\% of Inc. 500 companies used blogs, while $41 \%$ of colleges and universities did the same. The results also showed that private schools have been much faster in adopting social communication than public schools, Grljević \& Bošnjak (2012).

The paper Davis et al (2013) points out that research related to the effects of social media use on college student academic performance, outcomes, and attainment is quite scarce. As presented in Pearson Social Media Survey (2010), Junco (2011), and Chuck (2012), as well as in additional researches presented by Davis, Deil-Amen, Rios-Aguilar, \& Canche (2013), mostly the conclusion is that there is no impact of Facebook usage on academic performance. However, Twitter has certain 
impact on increasing grades, Junco, Heibergert, \& Loken (2010). "The study showed how Twitter can be leveraged to support students' academic engagement, psychosocial development, and Chickering and Gamson's seven principles for good practice in undergraduate education, including enhanced faculty-student contact, cooperative and active learning, prompt feedback, maximal time on task, the communication of high expectations, and respect for diversity.”

As stated by Davis et al. (2013), some researches addressed the issues of social media sites usage regarding of demographics. Different researches proved that differences in usage exist between different ethnic groups, as well as individuals with different financial status (more income, more connectivity through different devices).

We have also pointed out that when evaluating usage of social media sites among students, it is important to understand that different user personalities engaging in social media conversations produce variety of groups and different usage profiles. One of the goals of the research presented in our article is to identify different user profiles among prospect students of Faculty of Economics Subotica, Serbia. This is considered to be an essential step for design of enrollment marketing strategy and attraction of prospects.

\section{Research Fundamentals}

In order to estimate feasibility of conducting social media analytics, in particular sentiment analysis, in the field of higher education in Serbia, empirical research had to be conducted. As sentiment analysis involves many steps and is time consuming it was desirable to examine firstly the current behavior of students on social media sites (which sites they use, in which way, the frequency of use, etc.) that would revile a profile of modern student, and to examine whether their behavior can produce a sufficient quantity of inputs for these analysis in a long run, Grljević \& Bošnjak (2012).

The main research questions or problems addressed in presented paper:

- Are social media sites utilized by prospective students in general and in particular for educational purposes, in which manner and to what extent?

- What is the profile of typical online user behavior among prospective students of the Faculty of Economics Subotica?

The main objective of conducted research was to establish the level of presence and utilization of social media sites in everyday life of future students of Faculty of Economics Subotica, and additionally in the process of education.

For the purpose of the research a survey was conducted among future students of the faculty. From a sample of $n=791$ enrolled students, $40 \%$ responded. Out of 303 respondents who completely filled the survey questionnaire, 211 were female, while 92 were male.

In the formulation of the questionnaire checklist technique and the method of pair-wise comparison was used. Prior to final formulation and distribution of questionnaire to the subjects, a pilot study was conducted with the goal to improve questionnaire, and to test the validity of the results and conclusions that can be obtained over data collected by this means. Additional information about the pilot study can be found in Grljević \& Bošnjak (2012). The questionnaire includes 13 questions grouped into three sets that evaluate different aspects of social media sites usage:

- The first part of the questionnaire refers to the basic data about students from which can be obtained main demographic characteristics and previous success in school.

- The second part of questions is related to the familiarity of respondents with various specific social media sites, the frequency of visiting these sites, purposes and motives for networking and 
sharing the content through these sites, as well as the frequency of performing certain activities on these sites.

- The third set of questions examines the use of social media sites for a college selection, for the education needs (time spent online, frequency of publication of content related to the school, engagement in certain activities on these sites, and association with professors).

Additional questions are presented. They refer to activities of respondents on blogs and forums, and the reasons for not using social media sites more frequently. A field is also left in which respondents could have written their opinion or describe their experience with the use of social media sites and networks.

In order to answer the research questions, some fundamental statistical overviews were used, and in order to profile students in accordance to their habits and motivations in social media sites usage, as well as the frequency of carrying out certain activities on these sites, Simple K-Means cluster analysis was conducted.

\section{Research Results}

Figure 1 illustrates the frequency of usage for some of the most popular internet social media sites.

Figure 1: Familiarity and frequency of use of internet social media sites expressed in percentage

\section{Source: Authors}

The following can be concluded from the figure:

- All respondents are familiar with the Facebook, and the majority visits this site on the daily bases (approximately $81 \%$ of respondents). 
- Two social networking sites that follow Facebook, MySpace and Google+, are mostly familiar among respondents. However, as Figure 1 illustrates, most of the respondents do not visit MySpace, while Google+ is fairly represented among respondents and it is visited on the daily bases or every few days, what can be characterized as frequent usage.

- Although Twitter is one of the most popular microblogging sites, this kind of communication is not interesting among respondents. Given the Twitter has less social and more informative character, it can be concluded that this group of social media users prefers entertainment oriented sites.

- As stated in Poljak (2012), the average age of Twitter users is 31 years, while that of MySpace is 26 years. It can be concluded that obtained structure of responses and interest for Twitter and MySpace potentially is dependent on the age of users or the way communication is held on these sites.

- YouTube, Web site for social sharing and commenting on videos, is even more popular than Facebook among respondents. 95\% of respondents visit the site frequently (daily - 84\% or every few days $-11 \%)$.

- Wikipedia is the best known site from the group of Wikis where interaction between users and site is characterized by adding articles and editing existing ones. Wikipedia is very popular among respondents, $51 \%$ frequently visits this site (every few days or daily).

An interesting finding is that forums and blogs are not attractive to the respondents, and that the vast majority of them do not use sites of this type.

Simple K-Means clustering was conducted in order to group similar students' behavior on social media sites into certain number of clusters, resulting with the clusters that will include students with the most similar online behavioral patterns and the most different between clusters.

Profiling students according to the frequency of certain activities they conduct on social media sites resulted in four clusters. Table 1 illustrates cluster assignments obtained in Weka tool for data mining, Weka (2013).

\begin{tabular}{|c|c|c|c|c|}
\hline & Cluster1 & Cluster2 & Cluster3 & Cluster4 \\
\hline watch videos & $\begin{array}{c}\text { very } \\
\text { frequently }\end{array}$ & $\begin{array}{c}\text { very } \\
\text { frequently }\end{array}$ & frequently & $\begin{array}{c}\text { very } \\
\text { frequently }\end{array}$ \\
\hline comment videos & frequently & rarely & never & never \\
\hline read blogs and wikis & frequently & frequently & rarely & frequently \\
\hline comment blogs and wikis & never & rarely & never & never \\
\hline write blogs or wikis & never & rarely & never & never \\
\hline visit social media sites & $\begin{array}{c}\text { very } \\
\text { frequently }\end{array}$ & $\begin{array}{c}\text { very } \\
\text { frequently }\end{array}$ & $\begin{array}{c}\text { very } \\
\text { frequently }\end{array}$ & $\begin{array}{c}\text { very } \\
\text { frequently }\end{array}$ \\
\hline read comments on forums & $\begin{array}{c}\text { very } \\
\text { frequently }\end{array}$ & frequently & rarely & frequently \\
\hline comments on forums & never & rarely & never & never \\
\hline
\end{tabular}

Source: Authors 
Figure 2 illustrates cluster assignments represented numerically, where value 1 is equivalent to never, 2 to rarely, 3 to frequently, and 4 to very frequently. As the figure illustrates, although values for certain attributes repeat for each cluster, clusters are mostly distinct. The reason is that, for instance, $64 \%$ of respondents watch or listen to online videos on daily bases i.e. very frequently, while $27 \%$ is doing the same frequently, therefore the value of this attribute is the same in three out of four clusters. Respondents visit social networking sites on a daily bases and therefore the value for this attribute (orange column on the graph) is the same in all four clusters.

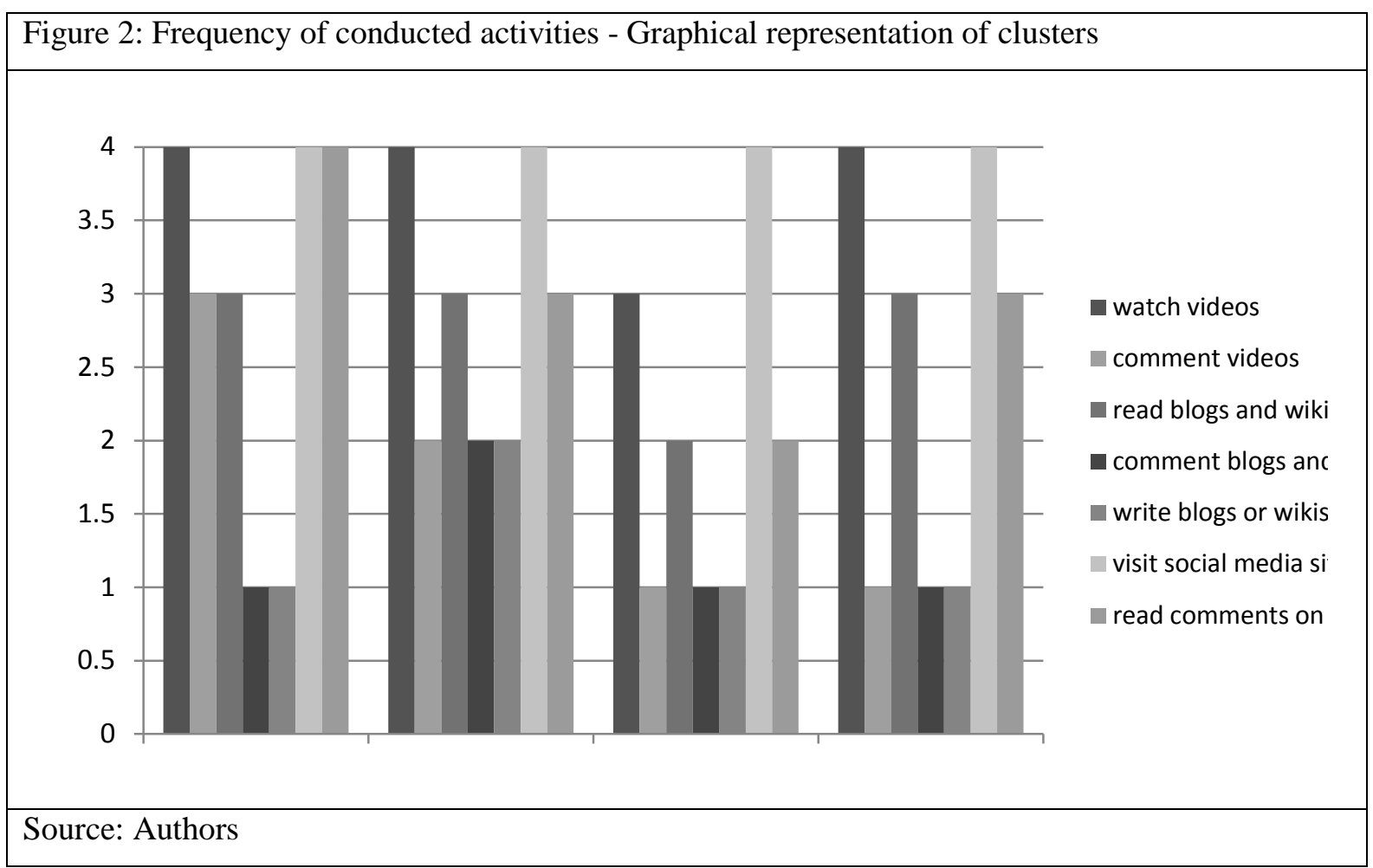

Cluster 1: Respondents who intensively and very frequently read comments on forums, frequently comment videos, read blogs or wikis, and who are not active creators of content on the Internet (do not write blogs, comment posts of others on forums or blogs). It can be concluded that opinion of this group of future students is greatly shaped by the content found on the Internet.

Cluster 2: More active creators of content. In addition to frequent reading of the content on forums and blogs, future students in this cluster represent the only group of content creators. Although rarely, this group is active on blogs and forums (they create new content and comment existing).

Cluster 3: Passive students. Unlike other clusters, students in this cluster watch or listen to online videos several times a week or once a week which cannot be characterized as intense activity. They never leave comments on the Internet and in accordance with their activities it can be concluded that social media sites are primarily used for occasional entertainment purposes.

Cluster 4: Students of this cluster frequently visit blogs, forums and wikis, but do not have freedom of expression to leave comments. They do not shape opinion in their online community.

Table 2 illustrates cluster assignments when students are profiled in accordance to their preferred motives and habits for online social engagement. Figure 3 illustrates graphical representation of cluster one. 
CBU I NTERNATIONAL CONFERENCE ON I NNOVATION, TECHNOLOGY TRANSFER AND EDUCATION

\begin{tabular}{|c|c|c|c|c|}
\hline \multicolumn{1}{|l|}{ Table 2: Motives and habits for social engagement - Cluster assignments } \\
\hline & Cluster 1 & Cluster 2 & Cluster 3 & Cluster 4 \\
\hline Maintain contact & yes & yes & yes & yes \\
\hline Make new friendship & no & no & yes & no \\
\hline More information about contacts & no & no & no & no \\
\hline State an opinion & no & no & yes & no \\
\hline Comment & no & no & no & no \\
\hline Watch videos & yes & yes & yes & yes \\
\hline Share content & yes & no & yes & yes \\
\hline Blog/wiki & yes & no & no & no \\
\hline Specialized groups & yes & no & no & no \\
\hline Search for content & yes & no & yes & yes \\
\hline Events & yes & no & yes & no \\
\hline Games & no & no & no & no \\
\hline School activities & yes & no & yes & yes \\
\hline Communication with pupils & yes & no & yes & yes \\
\hline Communication with teachers & no & no & yes & no \\
\hline Brands & yes & no & no & no \\
\hline Duthors & yes & no & no \\
\hline
\end{tabular}

\begin{tabular}{|l|l|}
\hline Figure 3: Clusters of motives and habits for social media engagement - cluster one \\
\hline & " keep contact \\
& " videos \\
& " share content \\
& " blog/wiki \\
& " spec. group \\
& " search for content \\
& " events \\
& " school activities \\
& " communicate with pupils \\
& " brands \\
\hline Source: Authors & \\
\hline
\end{tabular}

Students of cluster one, presented in Figure 3, tend to keep their familiar group of people in online surroundings with quite a range of motives and activities in social connecting. Entertainment motive is always present when it comes to social media sites, but aside of that, students in this cluster could be considered as moderate influential users since they write blogs and wikis and plan and invite others to different events. Following favorite brands or subjects of interest is particularly interesting for this group of online social media behavior. Therefore, belonging to a specialized groups and seeking for a 
unique experience with a favorite brand or institution represents the unique perspective of online social media connectivity of this cluster. In addition, students in this cluster use social media sites to communicate with other scholars about school materials, lecture theses, homework and other educational purposes, as well as for monitor and follow school activities.

Cluster two assignments are presented in Figure 4. As it can be noted, this cluster is present in online social media world solely for entertainment purposes. They maintain contact whit known friends and watch and listen to online videos.

\begin{tabular}{|l|}
\hline Figure 4: Clusters of motives and habits for social media engagement - cluster two \\
\hline \\
Source: Authors contact \\
- videos
\end{tabular}

Cluster three is presented in Figure 5. These are influential users, since one of the main motives for social media connectivity is to express opinions and views. They tend to extend their connections base by reaching the new people through social media sites. They are creators of new content and events. Social media sites are not view solely as an entertainment sites, but also as a mean for improved communication for educational purposes between pupils and teachers.

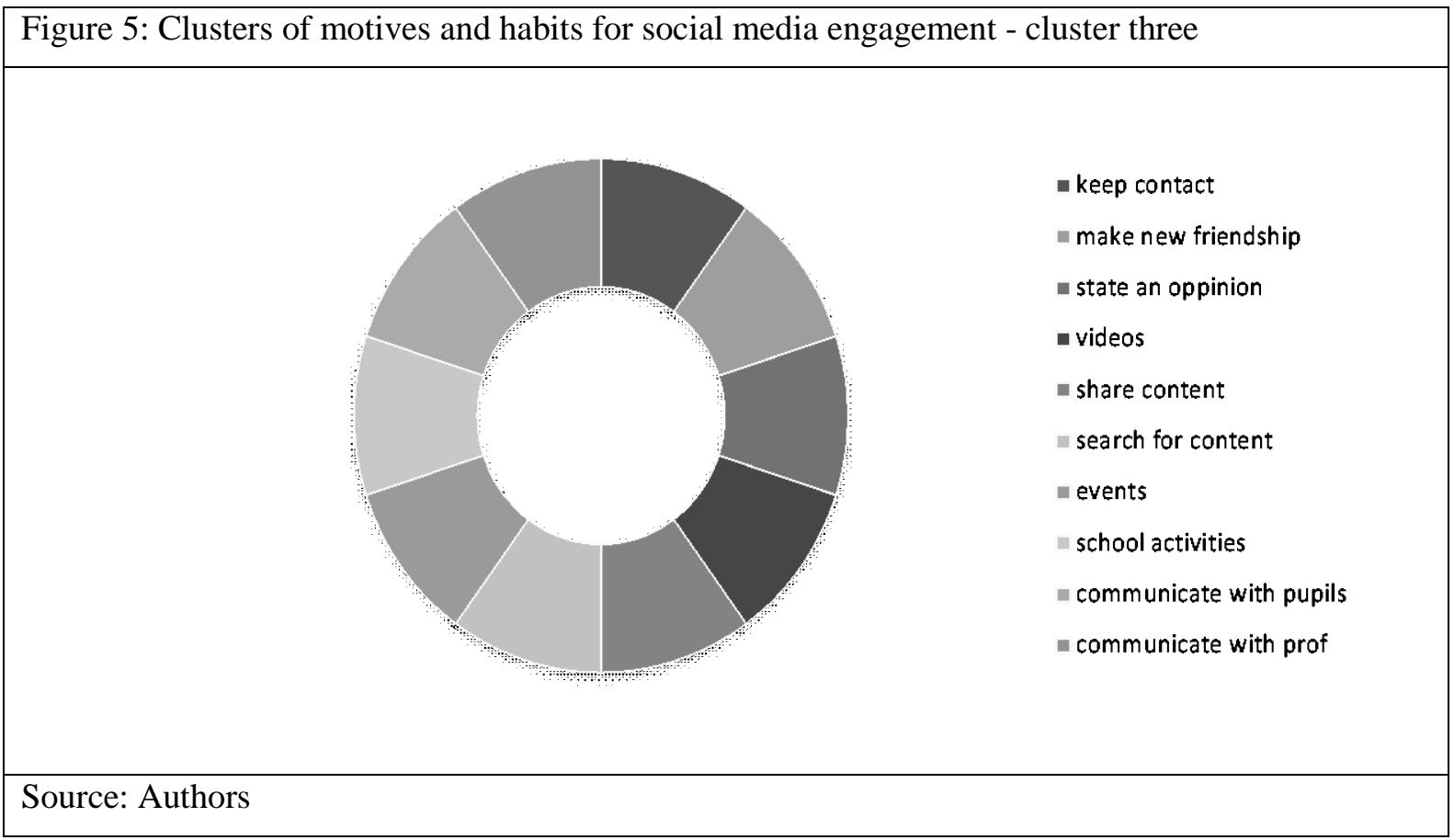


Cluster four is presented in Figure 6. This cluster is on a transit to more qualitative usage of social media sites. Students of this cluster use social media sites for informational purposes and somewhat for educational purposes.

Figure 6: Clusters of motives and habits for social media engagement - cluster four

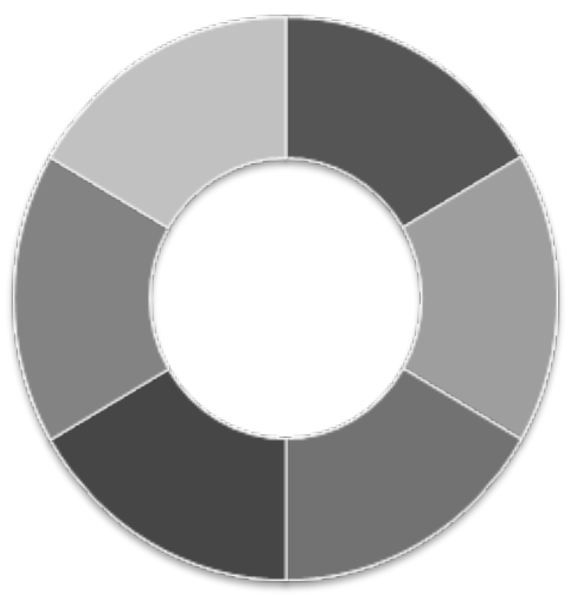

keep contact

videos

- share content

- search for content

school activities

communicate with pupils

Source: Authors

\section{Conclusion}

Since different user personalities, engaged in social media communication, produce variety of groups and usage profiles, identification of different user profiles among prospect students seems like an essential step. Discovering habits and preferences of future students towards the social media on the Internet brings many benefits and advantages to the institution, especially in the domain of attraction of new students and enrollment marketing strategy. Desired candidate profiling and analysis of their behavior on the Web can increase brand awareness and increase conversion rate.

Social media analytics, especially sentiment analysis and opinion mining, applied to user generated content on social media sites, can help in analyzing the reputation of the institution, as well as individual courses or majors. The results of these analyzes can be used to optimize the popularity of the course, for personalization of media messages in the stage of attraction or recruiting new students, as well as targeting the desired target group.

Although very interesting and useful, similar studies have not been performed. Therefore, the presented results in this article are particularly interesting. Our current findings show that there are distinct online behavioral patterns among students. There are students who only use social media sites for entertainment purposes, they do not influence other peoples' opinion neither their opinion can be influenced by others, on the other hand small portion of respondents are influential users that shape public opinion and should be reached and motivated to promote faculty in the finest manner. Thus, word-of-mouth marketing is a very powerful tool.

Future research directions are reflected in the detailed profiling of students based on extensive data collected by questionnaire. First of all, profiling students in accordance to their habits of social media sites usage in education and communication with other students regarding education, the relationship between students' grades and the way they use social media sites - whether behavior on social media 
sites or social networks determines successful and unsuccessful students. These findings could help faculty improve relationship with students and reach trouble students in order to provide them with help in education.

\section{References}

Chuck, M. (2012). Social networking usage and grades among college students. Retrieved from, http://www.unh.edu/news/ docs/UNHsocialmedia.pdf

Davis, C. H. F., Deil-Amen, R., Rios-Aguilar, C., \& Canche, M. S. G. (2013). Social Media in Higher Education a literature review and research directions. Retrieved, February 19, 2013, from http://www.league.org/gettingconnected/files/Social\% 20Media\%20in\%20Higher\%20Education.pdf

Pang, B., \& Lee, L. (2008). Opinion Mining and Sentiment Analysis. Foundations and Trends - Information Retrieval, 2(12), 1-135. ISBN: 978-160-19815-0-9.

Grljevic, O., \& Bosnjak, Z. (2012). Znacaj analize sadrzaja socijalnih medija [The importance of social media content analysis]. YuInfo $18^{\text {th }}$ Conference and exhibition, 84-89. Kopaonik: Serbia. ISBN: 978-86-85525-09-4.

Grljevic, O., Seres, L., \& Debeljacki, R. (2012). Perspectives of social media analytics application in higher education in Serbia. ISIT 2012 Fourth International Conference on Information Technologies and Information Society. Dolenjske Toplice: Slovenia. ISBN: 978-961-93391-1-4.

Junco, R. (2011). The relationship between frequency of Facebook use, participation in Facebook activities, and student engagement. Computer \& Education, 58(1), 162-171.

Junco, R., Heibergert, G., \& Loken, E. (2010). The effect of Twitter on college student engagement and grades. Journal of Computer Assisted Learning, 27, 119-132.

Lithium (2012). Social Customer Community Software \& Social Media Marketing Solutions. Retrieved September 14, 2012, from http://www.lithium.com/

Ologie (2012). Social media and higher education. Retrieved January 5, 2012, from http://www.slideshare.net/leighhouse/ social-media-higher-ed

Pearson Social Media Survey (2010). Retrieved January 10, 2012, from http://www.slideshare.net/PearsonLearningSolutions/ pearson-socialmediasurvey2010,

Poljak, I. (2012). Psihologija Twittera [The Psychology of Twitter]. Retrieved from http://www.psihoverzum.com/ psihologija-twittera/

Weka (2013). Data mining software in Java. Retrieved February 9, 2013, from http://www.cs.waikato.ac.nz/ml/weka/ 